\title{
On the Thermal Performance of the Vapor Chamber with Micro-channel for Unmixed Air Flow Cooling
}

\section{Paisarn Naphon* and Songkran Wiriyasart}

Thermo-Fluids and Heat transfer Enhancement Lab (TFHT), Department of Mechanical Engineering, Faculty of Engineering, Srinakharinwirot University, 63 Rangsit-Nakhornnayok Rd., Ongkharak, Nakhornnayok, 26120,Thailand

*E-mail: paisarnn@swu.ac.th

\begin{abstract}
Numerical and experimental results on the thermal performance of vapor chamber with and without micro-channel under constant heat flux are presented. The mathematical model of the vapor chamber is a two-phase closed chamber with wick sheet and a wick column. A finite volume method with structured uniform grid method system is applied to solve the model. Effects of micro-channel on the temperature distribution of the vapor chamber are considered. The results obtained from the model are verified with those from the measured data. The experimental tests are carried out and good agreement is obtained with the numerical results. These numerical results are useful for the design to improvement thermal performance of the vapor chamber and also diminished the expense and time of the real test.
\end{abstract}

Keywords: Thermal performance, vapor chamber, micro-channels.

ENGINEERING JOURNAL Volume 19 Issue 1

Received 20 February 2014

Accepted 7 September 2014

Published 30 January 2015

Online at http://www.engj.org/

DOI:10.4186/ej.2015.19.1.125 


\section{Introduction}

As compare to other cooling techniques such as fans, thermoelectric module, liquid pump loop device, the vapor chamber cooling technique has simple structures, no moving parts and does not use electricity. Heat dissipation increased but in contrary the size of the processor reduced. For the electronic cooling with vapor chamber, the bottom copper plate is the evaporator section that may be mounted on the electronic components to absorb the generated heat, and the other is the condenser section which heat is transferred to heat sink and air, respectively. Li et al. [1, 4] experimentally studied effects of the width, height and number of fins and of the Reynolds number on the thermal performance. Tsai et al. [2] experimentally investigated effects of heating power, fill ratio of working fluid, and evaporator surface structure on the vapor chamber thermal performance. Wang et al. [3] performed the thermal performance of a board-level high performance flip-chip ball grid array package equipped with vapor chamber as cooling system. Wong et al. [5] experimentally studied the vapor chamber performance with water, methanol or acetone as working fluid. Attia et al. [6] studied the effective thermally of vapor chamber with different charge ratios for electronic cooling. Choi et al. [7] considered the performance of active CPU cooling heat of personal computer. Crepinsek and Park [8] experimentally investigated the mechanical pump-assisted and capillarydriven two-phase cooling loop. Elnaggar et al. [9] numerically studied the vertically oriented twin U-shape heat pipe. Ji et al. [10] designed and tested a copper foam based vapor chamber with sintering column. Naphon et al. [11, 16] experimentally investigated the thermal cooling of vapor chamber for cooling computer processing unit and hard disk drive of the personal computer. Two different configurations of the vapor chambers with de-ionized water as working fluid are tested under the real operating conditions of PCs. Parametric studies including different aspect ratios, fill ratios, and operating conditions of PC on the CPU temperature are considered. Reyes et al. [12] experimentally and theoretically studied the behavior of a vertically placed vapor chamber based heat spreader intended for avionics applications. Saenen and Baelmans [13] numerically studied the micro channel heat sinks using two-phase flow boiling have excellent potential for cooling high heat flux electronic devices. Chen et al. [14] studied the vapor chambers for spreading and heat transfer because of phase change phenomena. Hassan and Harmand [15] considered effects of nanofluid types and wick porosities on thermal performance of flat vapor chamber. A good agreement is found between the results of the numerical and experimental work and the numerical results. Peng et al. [17] studied the performance of a novel flat plate heat pipe with different fill ratios for electronic cooling. Peng et al. [18] studied a new pattern of wick in vapor chamber. Tsai et al. [19] studied the efficient cooling systems of the vapor chamber heat spreader two-phase heat transfer device.

To the best of author' knowledge, as mentioned above, the numerous papers presented the study on the heat transfer characteristics of the vapor chamber. However, there are rarely researches present the study on the effect of micro-channel in the vapor chamber on the thermal cooling of the vapor chamber. Therefore, the objective of this paper is to numerically study the effect of micro-channel on the thermal performance and temperature distribution of the vapor chamber. Experiments are conducted to obtain the temperature distribution and thermal performance for verifying the numerical study.

\section{Experimental Apparatus and Procedure}

\subsection{Test Loop}

A schematic diagram of the experimental apparatus is shown in Fig. 1. The test loop consists of a test section, chilled air loop and data acquisition system. Air is used as coolant working fluid. The loop wind tunnel is rectangular air duct fabricated from acrylic, having the length of $200 \mathrm{~cm}$. The duct is insulated with $5 \mathrm{~mm}$ thick Aeroflex standard sheet. Air in the wind tunnel is suctioned by the centrifugal fan into the channel and is passed through a test section, straightener, and then discharged to the atmosphere. The flow rate of air is measured by nozzle with accuracy of $0.2 \%$ of full scale. The pressure drops across the test section and the nozzle are measured by the differential pressure transducer with an accuracy of $0.02 \%$ of full scale. There are four pressure taps on each wall upstream and downstream of the test section. The type $\mathrm{T}$ copper-constantan thermocouples with an accuracy of $0.1 \%$ of full scale are employed to measure air temperatures. The inlet and outlet temperatures of air are measured by two and four thermocouples with 1 $\mathrm{mm}$ diameter probes extending into the duct in which the air flows, respectively. All the thermocouples probes are pre-calibrated by dry-box temperature calibrator with $0.01 \mathrm{oC}$ precision. 


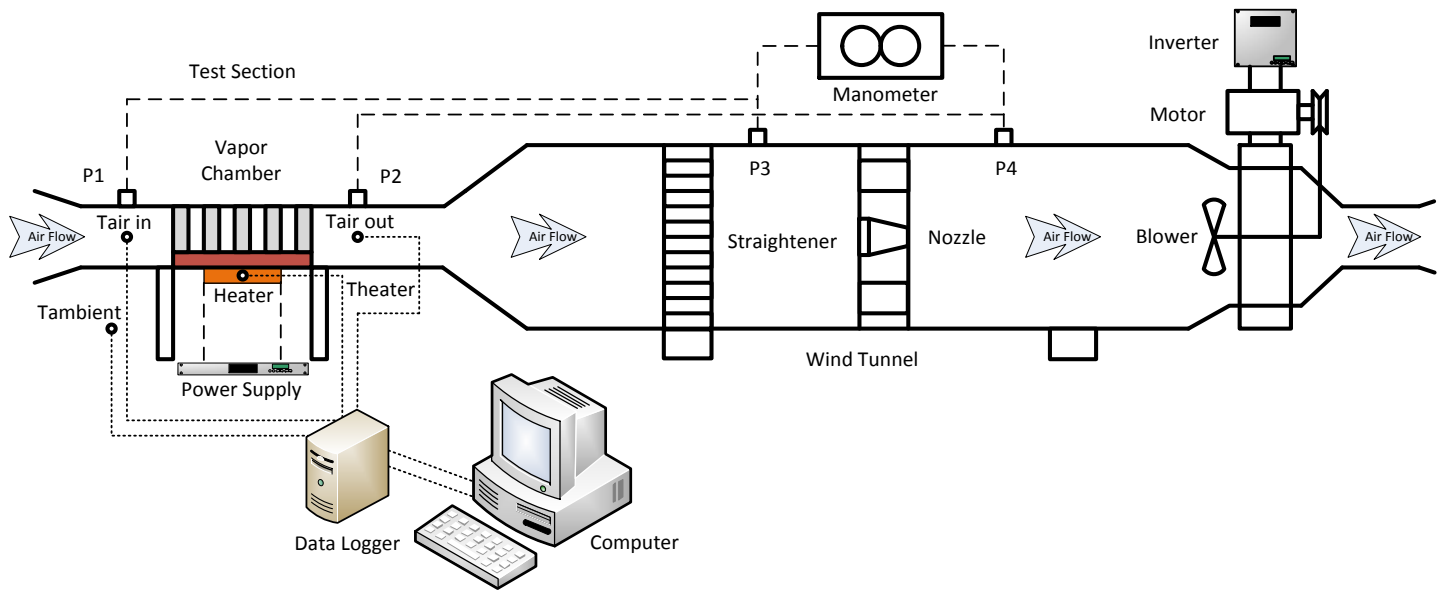

Fig. 1. Schematic diagram of the computational domain.

\subsection{Test Sections}

The vapor chamber cooling system consists of heater unit, the vapor chamber, and heat sink unit. The schematic diagram of the vapor chamber unit is shown in Fig. 2. The vapor chamber is fabricated from copper plate which consists of bottom copper plate, wick sheet, sinter column, and top copper plate. The wick sheet and the sinter column are fabricated from the copper powder. The bottom copper plate is the evaporator section that may be mounted on heater to absorb the generated heat, and the other is the condenser section which heat is transferred to heat sink and air, respectively. In order to minimize thermal contact resistance between the heater-vapor chamber, vapor chamber-heat sink unit, a thin film of high thermal conductivity grease is used at their junction interface. The working fluid (de-ionized water) is evaporated on the heated side and condensed on the cooling side and then returns to the evaporator section under gravity. Type T copper-constantan thermocouples with an accuracy of $0.1 \%$ of full scale are employed to measure the temperatures. Four type $\mathrm{T}$ copper-constantan thermocouples are applied to measure the vapor chamber temperature. A groove within the chamber walls is machined and the high conductivity cement is utilized to embed the thermocouples within the chamber wall.

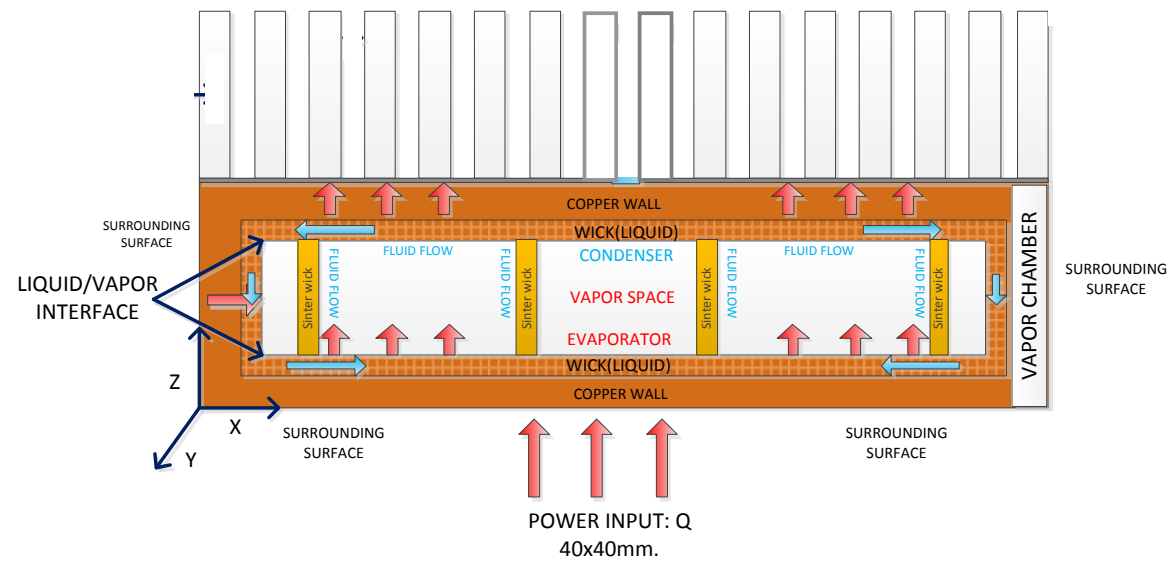

Fig. 2. Schematic diagram of computation domain and the cross section layers.

\subsection{Operating Conditions}

Experiments were conducted with various heat flux and flow rates of air entering the test section. In the experiments, air flow rate was increased in small increments while the supplied heat at the heat sink was kept constant. The supplied heat into the heat sink walls was adjusted to achieve the desired level by using electric heaters. The supplied power was calculated using the measured voltage and current supplied to the 
heaters. The supplied voltage and current to the heaters were measured by the digital clamp meter. The steady-state sensible heat gain by the air flow can be determined from an energy balance. In the present study, only the data that satisfy the energy balance conditions; $\left|Q_{\text {heater }}-Q_{a}\right| / Q_{\text {ave }}$ is less than $10 \%$, are used in the analysis. The average heat transfer, $Q_{a v e}$, is averaged from the supplied heat transfer to the heater and the removal heat transfer by cooling air. The temperature at each position and pressure drop across the test section were recorded three times. Data collection was carried out using a data acquisition system. The uncertainty and accuracy of the measurement are given in Table 1.

Table 1. Accuracy and uncertainty of measurements.

\begin{tabular}{lcc}
\hline Instruments & Accuracy & Uncertainty \\
\hline Voltage supplied by power source, V & $0.2 \%$ & \pm 0.5 \\
Current supplied by power source, I & $0.2 \%$ & \pm 0.5 \\
Air flow meter & $0.2 \%$ & \pm 0.5 \\
Thermocouple type T, Data logger, $\left({ }^{\circ} \mathrm{C}\right)$ & $0.1 \%$ & \pm 0.1 \\
Differential pressure transducer & $0.02 \%$ & \pm 0.02 \\
\hline
\end{tabular}

\section{Mathematical Modelling}

Based on the computational domains as shown in Fig. 3, a 3D transient thermal model coupled with a 3D transient hydrodynamic model is used to solve the model. The transient thermal and hydrodynamic models are used to calculate the vapor chamber temperature and pressure. The transient model is based on the numerical solution of the governing equations of the mass, momentum and energy equations.

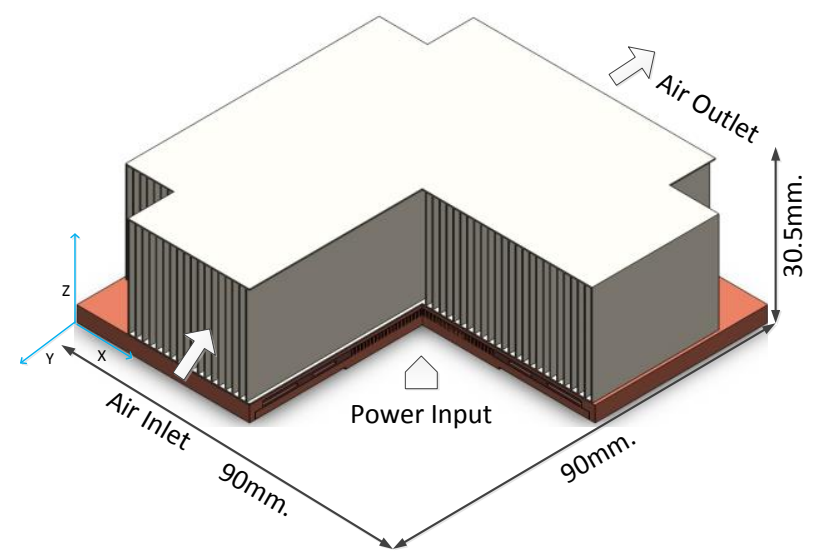

Fig. 3. Schematic diagram of the vapor chamber in the present simulation.

\section{For the vapor zone}

Continuity equation:

$$
\frac{\partial u}{\partial x}+\frac{\partial v}{\partial y}+\frac{\partial w}{\partial z}=0
$$

Momentum equation:

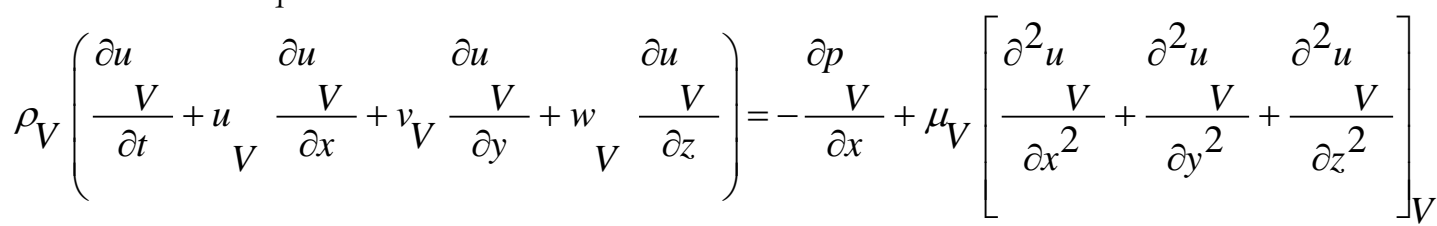

$$
\begin{aligned}
& \rho_{V}\left(\begin{array}{cccc}
\frac{\partial v}{\partial t}+u & \frac{\partial v}{\partial x}+v_{V} & \frac{\partial v}{\partial y}+w & \frac{\partial v}{\partial z}
\end{array}\right)=-\frac{\partial p}{\partial y}+\mu_{V}\left[\begin{array}{l}
\partial^{2} v \\
\frac{V}{\partial x^{2}}+\frac{\partial^{2} v}{\partial y^{2}}+\frac{\partial^{2} v_{V}}{\partial z^{2}}
\end{array}\right]_{V}
\end{aligned}
$$


$\rho_{V}\left(\begin{array}{cccc}\frac{\partial w}{\partial t}+u & \frac{\partial w}{V} \frac{V}{\partial x}+v & \frac{\partial w}{\partial y}+w & \frac{\partial w}{\partial z}\end{array}\right)=-\frac{\partial p}{\partial z}+\mu_{V}\left[\begin{array}{l}\partial^{2} w \\ \frac{V}{\partial x^{2}}+\frac{\partial^{2} w}{\partial y^{2}}+\frac{\partial^{2} w}{\partial z^{2}}\end{array}\right]_{V}$

Energy equation:

$$
\left(\rho C_{p}\right)_{V}\left(\frac{\partial T}{\partial t}+u_{V} \frac{\partial T}{\partial x}+v_{V} \frac{\partial T}{\partial y}+w_{V} \frac{\partial T}{\partial z}\right)=\lambda_{V}\left(\frac{\partial^{2} T}{\partial x^{2}}+\frac{\partial^{2} T}{\partial y^{2}}+\frac{\partial^{2} T}{\partial z^{2}}\right)
$$

\section{For the wick zone}

Continuity equation:

$$
\frac{\partial u}{\partial x}+\frac{\partial v}{\partial y}+\frac{\partial w}{\partial z}=0
$$

Momentum equation:

$$
\begin{gathered}
\frac{\rho}{\varepsilon}\left(\frac{\partial u_{l}}{\partial t}+u_{l} \frac{\partial u_{l}}{\partial x}+v_{l} \frac{\partial u_{l}}{\partial y}+w_{l} \frac{\partial u_{l}}{\partial z}\right)=-\frac{\partial p_{l}}{\partial x}-\frac{\mu_{l}}{K} u_{l}+\frac{\mu_{l}}{\varepsilon}\left[\frac{\partial^{2} u_{l}}{\partial x^{2}}+\frac{\partial^{2} u_{l}}{\partial y^{2}}+\frac{\partial^{2} u_{l}}{\partial z^{2}}\right]-\frac{C_{E}}{K}|V| V \\
\frac{\rho}{\varepsilon}\left(\frac{\partial v_{l}}{\partial t}+u_{l} \frac{\partial v_{l}}{\partial x}+v_{l} \frac{\partial v_{l}}{\partial y}+w_{l} \frac{\partial v_{l}}{\partial z}\right)=-\frac{\partial p_{l}}{\partial y}-\frac{\mu_{l}}{K} u_{l}+\frac{\mu_{l}}{\varepsilon}\left[\frac{\partial^{2} v_{l}}{\partial x^{2}}+\frac{\partial^{2} v_{l}}{\partial y^{2}}+\frac{\partial^{2} v_{l}}{\partial z^{2}}\right]-\frac{C_{E}}{K}|V| V \\
\frac{\rho}{\varepsilon}\left(\frac{\partial w_{l}}{\partial t}+u_{l} \frac{\partial w_{l}}{\partial x}+v_{l} \frac{\partial w_{l}}{\partial y}+w_{l} \frac{\partial w_{l}}{\partial z}\right)=-\frac{\partial p_{l}}{\partial z}-\frac{\mu_{l}}{K} u_{l}+\frac{\mu_{l}}{\varepsilon}\left[\frac{\partial^{2} w_{l}}{\partial x^{2}}+\frac{\partial^{2} w_{l}}{\partial y^{2}}+\frac{\partial^{2} w_{l}}{\partial z^{2}}\right]-\frac{C_{E}}{K^{0.5}}|V| V
\end{gathered}
$$

Energy equation:

$$
(\rho C)_{l}\left(\frac{\partial T}{\partial t}+u_{l} \frac{\partial T}{\partial x}+v_{l} \frac{\partial T}{\partial y}+w_{l} \frac{\partial T}{\partial z}\right)=\lambda_{l}\left(\frac{\partial^{2} T}{\partial x^{2}}+\frac{\partial^{2} T}{\partial y^{2}}+\frac{\partial^{2} T}{\partial z^{2}}\right)
$$

For the vapor chamber wall

$$
(\rho C)_{W} \frac{\partial T}{\partial t}=\lambda_{W}\left(\frac{\partial^{2} T}{\partial x^{2}}+\frac{\partial^{2} T}{\partial y^{2}}+\frac{\partial^{2} T}{\partial z^{2}}\right)
$$

\section{For the liquid coolant}

Based on the computational domains as shown in Figure 3, the following assumptions are made:

- Fluid flow and heat transfer are in steady-state and three dimensional.

- Single phase fluid flow is laminar flow.

- Effects of gravitational force and radiation heat transfer are neglected.

- Properties of coolant and heat sink material are temperature independent.

- All the heat sink surfaces exposed to the surroundings are assumed to be insulated except the heat sink base plate where constant heat flux simulating the heat generation from electronic chip is specified. By considering the geometry and physical problem as shown in Fig. 3, the main governing equations can be written in the following form:

Continuity equation:

$$
\frac{\partial u}{\partial x}+\frac{\partial v}{\partial y}+\frac{\partial w}{\partial z}=0
$$

Momentum equation: 


$$
\begin{gathered}
\rho\left(u \frac{\partial u}{\partial x}+v \frac{\partial u}{\partial y}+w \frac{\partial u}{\partial z}\right)=-\frac{\partial p}{\partial x}+\mu\left[\frac{\partial^{2} u}{\partial x^{2}}+\frac{\partial^{2} u}{\partial y^{2}}+\frac{\partial^{2} u}{\partial z^{2}}\right] \\
\rho\left(u \frac{\partial v}{\partial x}+v \frac{\partial v}{\partial y}+w \frac{\partial v}{\partial z}\right)=-\frac{\partial p}{\partial y}+\mu\left[\frac{\partial^{2} v}{\partial x^{2}}+\frac{\partial^{2} v}{\partial y^{2}}+\frac{\partial^{2} v}{\partial z^{2}}\right] \\
\rho\left(u \frac{\partial w}{\partial x}+v \frac{\partial w}{\partial y}+w \frac{\partial w}{\partial z}\right)=-\frac{\partial p}{\partial z}+\mu\left[\frac{\partial^{2} w}{\partial x^{2}}+\frac{\partial^{2} w}{\partial y^{2}}+\frac{\partial^{2} w}{\partial z^{2}}\right]
\end{gathered}
$$

Energy equation:

$$
\rho c_{p}\left(u \frac{\partial T}{\partial x}+v \frac{\partial T}{\partial y}+w \frac{\partial T}{\partial z}\right)=\lambda\left(\frac{\partial^{2} T}{\partial x^{2}}+\frac{\partial^{2} T}{\partial y^{2}}+\frac{\partial^{2} T}{\partial z^{2}}\right)
$$

\section{Numerical Procedure}

By considering the geometry and physical problem as shown in Fig. 3, second-order upwind scheme and structured uniform grid system are used to discretize the main governing equations. Based on the control volume method, SIMPLEC algorithm of Van Doormal and Raithby [20] is employed to deal with the problem of velocity and pressure coupling. Effects of micro-channel in the vapor chamber on the temperature distribution are considered. In order to assess the accuracy of these computations, the grid independence is carried out in the analysis by adopting different grid distributions of 730,000, 840,000, and 910,000 for the vapor chamber with micro-channel and of 670,000, 770,000, and 910,000 for the vapor chamber without micro-channel. The grid independence test indicated that the grid systems of 840,000 and 770,000 ensure a satisfactory solution for the vapor chamber with and without micro-channel, respectively. As shown in Table 2, this is verified by the fact that the difference of the computed results of an average heat source temperature with grid finer than the 840,000 and 770,000 (e.g. 910,000 and 910,000) within 1\% for the vapor chamber with and without micro-channel, respectively. At the inlet section, inlet air temperature enters the test section at the uniform velocity. Velocity boundary condition is applied at the inlet section while the pressure boundary condition is used at the outlet section. In the present study, the commercial program ANSYS/FLUENT is employed as the numerical solver to solve the problem. The numerical computation is ended if the residual summed over all the computational nodes satisfies the criterion of 10-5. In order to obtain the numerical results, the calculations are conducted for unmixed air flow in a channel.

Table 2. Grid independent check.

\begin{tabular}{llcc}
\hline Models & Grid & $\begin{array}{c}\text { Heat source } \\
\text { temperature }\left({ }^{\circ} \mathbf{C}\right)\end{array}$ & ${ }^{\%}$ \\
\hline \multirow{2}{*}{ With microchannel } & $7.3 \times 10^{5}$ & 42.50 & - \\
\cline { 2 - 4 } & $8.4 \times 10^{5}$ & 42.98 & 1.12 \\
\hline \multirow{2}{*}{ Without microchannel } & $9.1 \times 10^{5}$ & 42.99 & 0.04 \\
\cline { 2 - 4 } & $6.7 \times 10^{5}$ & 46.15 & - \\
\cline { 2 - 4 } & $9.7 \times 10^{5}$ & 49.26 & 6.50 \\
\hline
\end{tabular}

\section{Results and Discussion}

The steady-state sensible heat gain by the air flow can be determined from an energy balance. In the present study, only the data that satisfy the energy balance conditions; $\left|Q_{\text {heater }}-Q_{a}\right| / Q_{\text {ave }}$ is less than $10 \%$, are used in the analysis. The average heat transfer, $Q_{a v e}$, is averaged from the supplied heat transfer to the heater and the removal heat transfer by cooling air. A number of results can be drawn from the output of the simulation but, because of the space limitation, only typical results are shown. To study the temperature distribution in the vapor chamber cooling unit, the results plotted in vertical and horizontal plane cutting 
across the test section. In order to obtain the numerical results, the calculations are conducted under average constant heat flux condition. Table 3 also shows the comparison between the predicted heat source temperatures and thermal resistance with the measured data. For the vapor chamber with micro-channel, the average error between the experimental data and the predicted results are $5.51 \%$ and $12.98 \%$ for the heat source temperature and thermal resistance, respectively. For the vapor chamber without microchannel, the predicted results are reasonable agreement with the measured data and gives average errors of $2.27 \%$ and $5.42 \%$ for the heat source temperature and thermal resistance, respectively.

Table 3. Comparison of the heat source temperature and thermal resistance obtained from the measured data and the predicted results.

\begin{tabular}{lcccccc}
\hline Models & $\begin{array}{c}\text { Predicted } \\
\text { results } \\
\left({ }^{\circ} \mathbf{C}\right)\end{array}$ & $\begin{array}{c}\text { Measured } \\
\text { data } \\
\left({ }^{\circ} \mathbf{C}\right)\end{array}$ & $\%$ Error & $\begin{array}{c}\text { Predicted } \\
\text { results } \\
\left({ }^{\circ} \mathbf{C} / \mathbf{W}\right)\end{array}$ & $\begin{array}{c}\text { Measured } \\
\text { data } \\
\left({ }^{\circ} \mathbf{C} / \mathbf{W}\right)\end{array}$ & \%Error \\
\hline With microchannel & 42.99 & 45.50 & 5.51 & 0.21 & 0.24 & 12.98 \\
Without micro-channel & 46.15 & 47.23 & 2.27 & 0.24 & 0.25 & 5.42 \\
\hline
\end{tabular}

The total thermal resistance of the vapor chamber cooling technique is the summation of the contact resistance, the evaporation resistance, the condensation resistance, and the convection resistance. In this study, the overall heat sink performance can be shown in the thermal resistance form. It is found that a larger vapor chamber temperature drop is found for a larger coolant flow rate. The reason for this is because a larger coolant flow rate results in lower capacity resistance and consequently lower heat sink thermal resistance. The micro-channel has significant effect on the heat transfer from the heat source to the coolant. Therefore, the thermal resistance obtained from the vapor chamber with micro-channel is lower than those from without micro-channel as shown in Fig. 4.

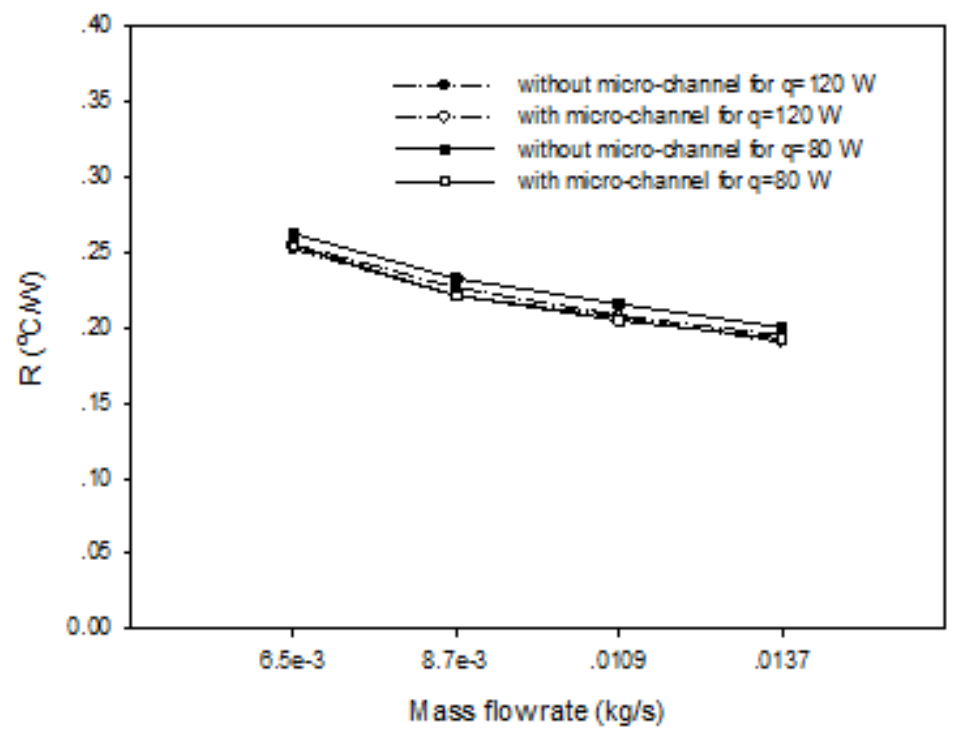

Fig. 4. Variation of thermal resistance of vapor chamber with and without micro-channel. 

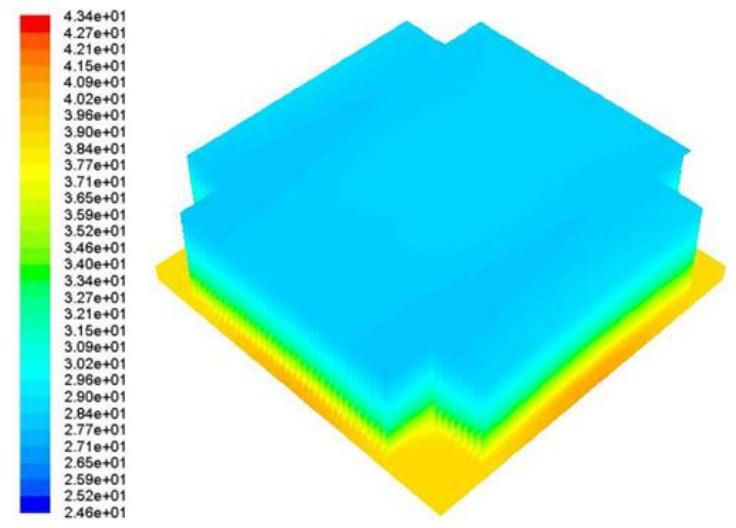

Isometric

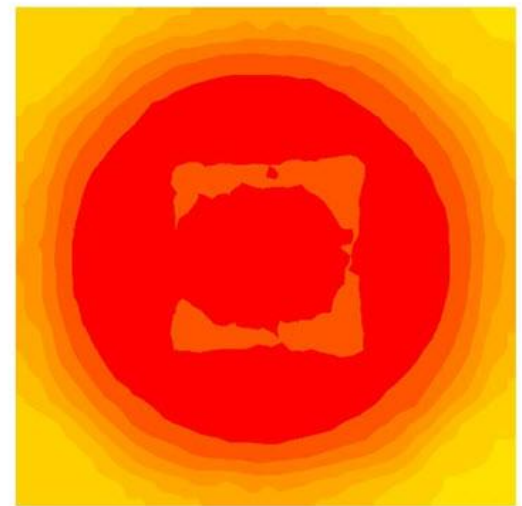

$\mathrm{Z}=0 \mathrm{~mm}$

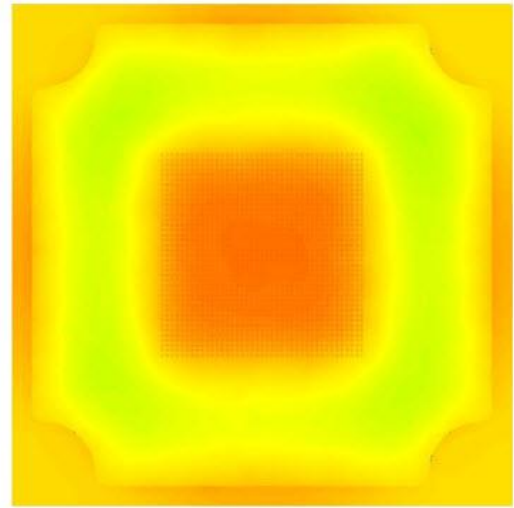

$\mathrm{Z}=2.5 \mathrm{~mm}$

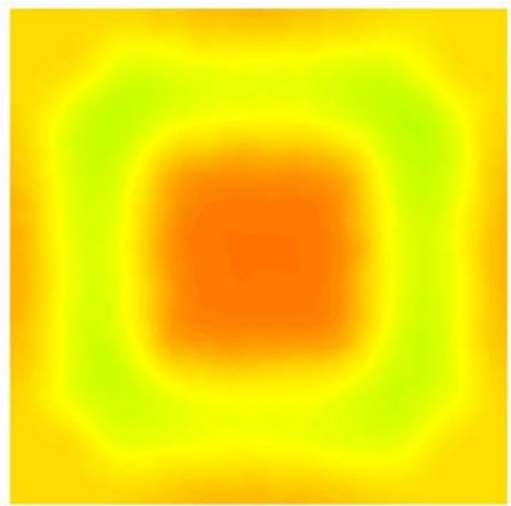

$\mathrm{Z}=4.5 \mathrm{~mm}$

Fig. 5. Temperature distribution for the vapor chamber with micro-channel.

Figure 5 shows the variation of the temperature distribution of the vapor chamber with microchannel for different Z-cross sections. The bottom copper plate is the evaporator section that may be mounted on the electrical heater to absorb the generated heat, and the other is the condenser section which heat is transferred to heat sink and unmixed air flow cooling, respectively. The cross sections in $Z$-axis at $Z=0$ $\mathrm{mm}, Z=2.5 \mathrm{~mm}$, and $Z=4.5 \mathrm{~mm}$ are represented the bottom surface, middle surface, and the top surface of the vapor chamber, respectively. It can be seen that the regions of concentrated high temperature are observed above the heating element in the bottom plate of the vapor chamber that lead to the accumulation of heat close to the heating zone. The generation of heat is spread more uniformly to the base plate as shown at $Z=0 \mathrm{~mm}$. At the middle surface of the vapor chamber $Z=2.5 \mathrm{~mm}$, it can be seen that the regions of concentrated high temperature are observed on the micro-channel zone. This is because the generated heat also is transferred by conduction through the base surface and micro-channel fin. In addition, the generated heat is absorbed by the working fluid inside the vapor chamber and evaporated on the bottom plate surface. At the top surface, the vapor is condensed and then returns to the evaporator section under gravity. Therefore, the temperature distribution at this region is tends to decrease especially at the vapor chamber. For $Z=4.5 \mathrm{~mm}$, the temperature distributions are similarly to those at $Z=2.5 \mathrm{~mm}$ as mention above. 


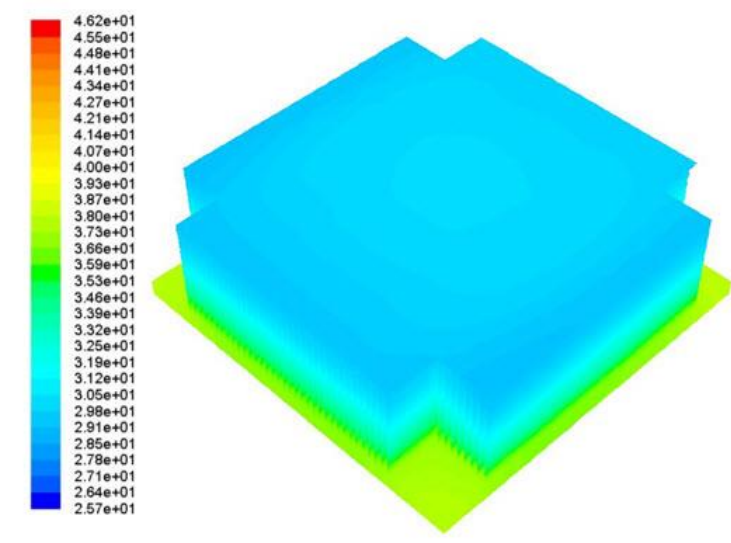

Isometric

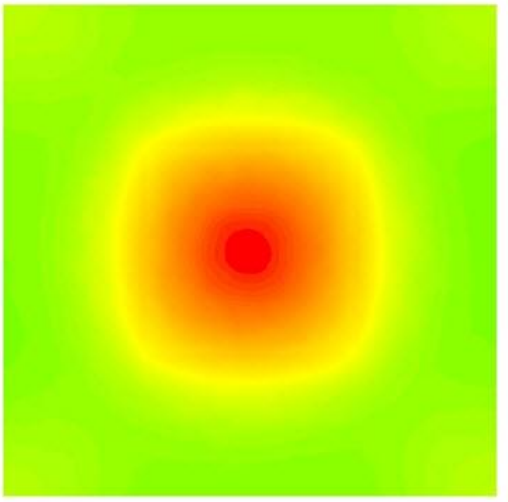

$\mathrm{Z}=0 \mathrm{~mm}$

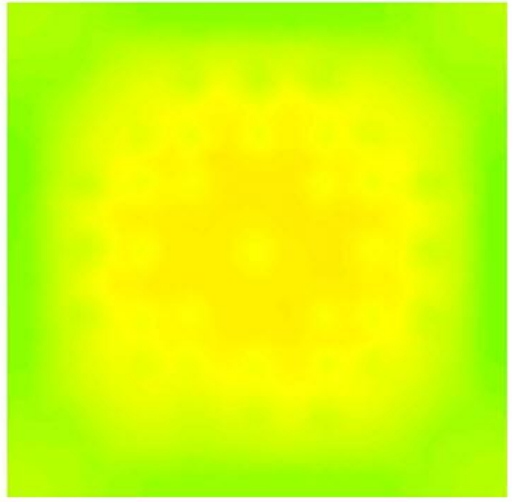

$\mathrm{Z}=2.5 \mathrm{~mm}$

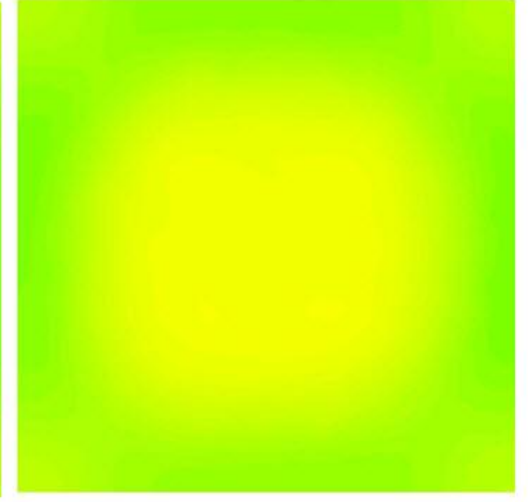

$\mathrm{Z}=4.5 \mathrm{~mm}$

Fig. 6. Temperature distribution for the vapor chamber without micro-channel.

Figure 6 shows the variation of the temperature distribution of the vapor chamber without microchannel for different Z-cross sections. An interior volume of the vapor chamber is occupied with the working fluid (without micro-channel). It can be seen that the regions of concentrated high temperature are observed above the heating element that lead to the accumulation of heat close to the heating region. The generation of heat is spread more uniformly to the base plate. For $Z=0 \mathrm{~mm}$, the generated heat is absorbed by the working fluid inside the vapor chamber and evaporated on the bottom plate surface. At the top surface, the vapor is condensed and then returns to the evaporator section under gravity. Therefore, the temperature distribution at this region is spread more uniformly as shown at $\mathrm{Z}=2.5 \mathrm{~mm}, \mathrm{Z}=4.5 \mathrm{~mm}$. Due to without heat conduction through the micro-channel, the generated heat are accumulated at the bottom plate of the vapor chamber. The maximum temperatures of the vapor chamber obtained from the vapor chamber without micro-channel are higher than those with micro-channel. In addition, the temperature distributions in the vapor chamber without micro-channel are more uniformly than those with microchannel. 

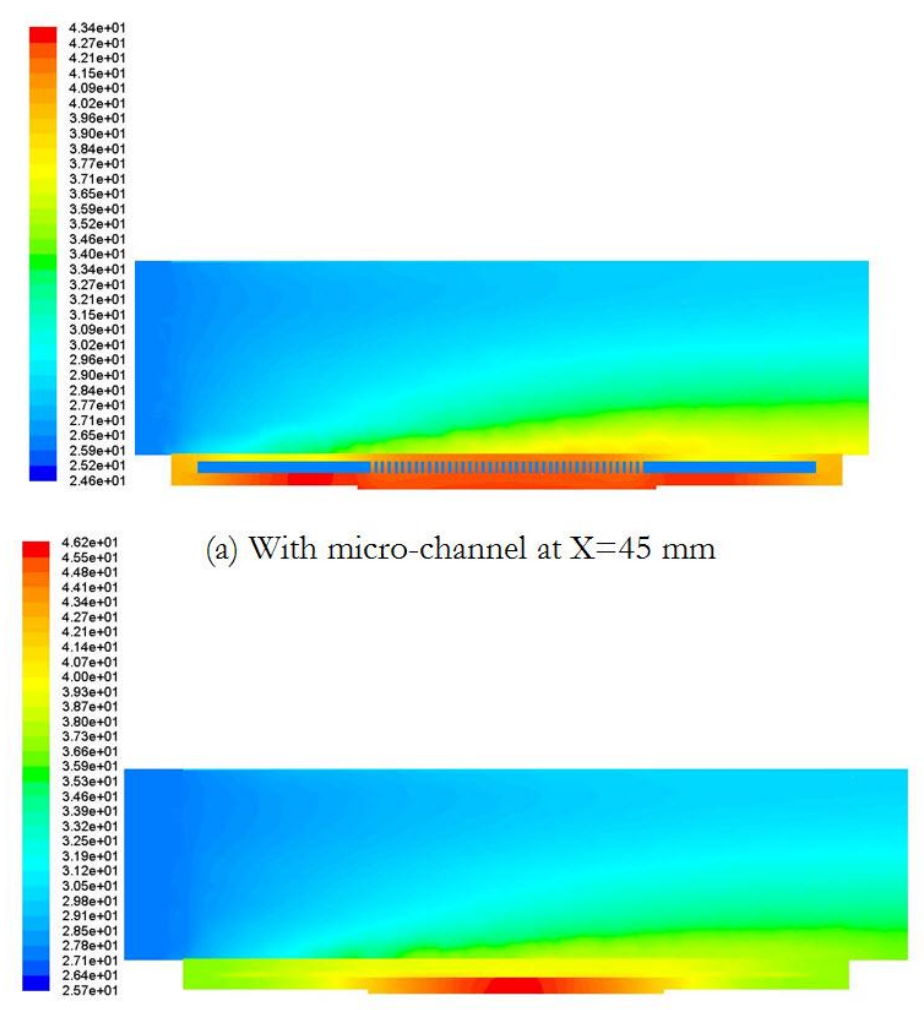

(b) Without micro-channel at $\mathrm{X}=45 \mathrm{~mm}$

Fig. 7. Temperature distribution for the vapor chamber at $\mathrm{X}=45 \mathrm{~mm}$; (a) with micro-channel; (b) without micro-channel.

The liquid working fluid absorbs heat from heat source and evaporates in the evaporator, and then moves toward the condenser. In the condenser the vapor releases heat to the ambiance and condenses into liquid. The generated heat is transferred by convection to the ambient. Figure 7 shows the variation of temperature distribution of the vapor chamber with and without microchannel for $\mathrm{X}=45 \mathrm{~mm}$. Due to nonuniformity velocity of fluid, the temperature distribution of the heat sink is not uniformity. The low temperature region of the heat sink occurs at the entrance region. This is because the heat transfer coefficient increases in this region. Due to the decrease temperature different between heat sink and coolant as fluid flowing close to the outlet region, temperature distribution of the of the solid phase heat sink in this region tends to increase as shown in Fig. 7. Figure 8 shows the variation of temperature distribution of the vapor chamber with and without microchannel for $Y=53 \mathrm{~mm}$. It can be seen that the high temperature zone occurs at the middle zone of the heat sink unit and then tends to slightly decrease for the both sizes of the heat sink unit. 


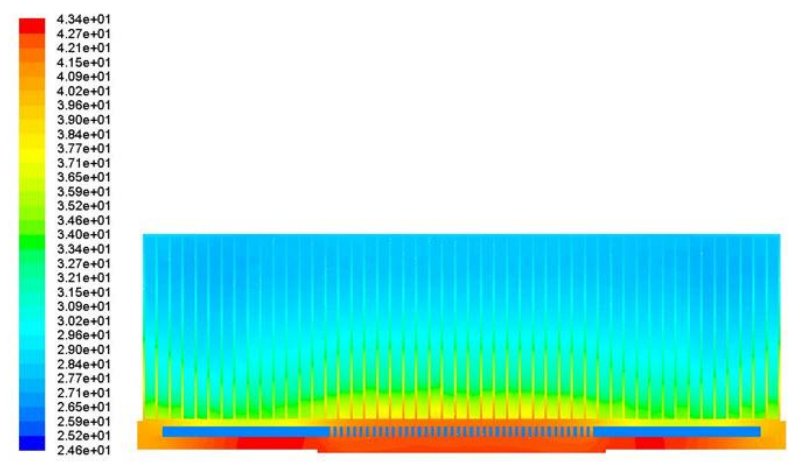

(a) With micro-channel at $\mathrm{Y}=53 \mathrm{~mm}$

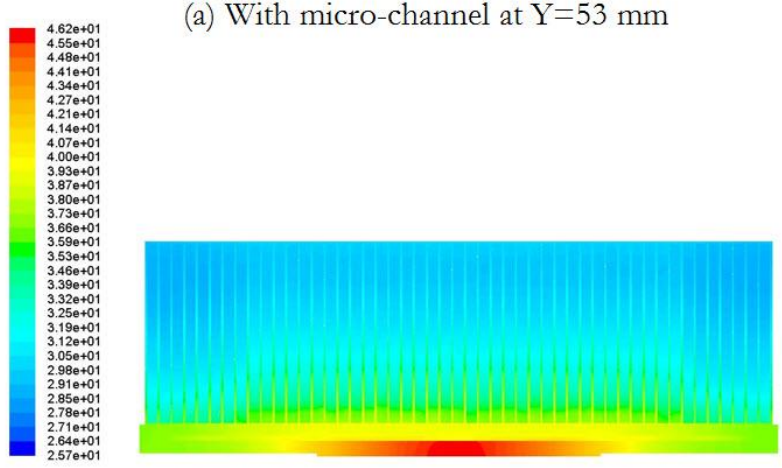

(b) Without micro-channel at $\mathrm{Y}=53 \mathrm{~mm}$

Fig. 8. Temperature distribution for the vapor chamber at $Y=53 \mathrm{~mm}$; (a) with micro-channel; (b) without micro-channel.

\title{
6. Conclusion
}

In the present study, the numerically and experimentally on the heat transfer characteristics of vapor chamber with unmixed air flow are studied. The results obtained from the vapor chamber without microchannel are compared with those with micro-channel. It is found that the micro-channel has significant effect on the temperature distribution and thermal resistance of the vapor chamber. This would improve the design consideration for the vapor chamber configuration. The results of this study are of technological importance for the efficient design of cooling systems of electronic devices to enhance cooling performance.

\section{Nomenclature}

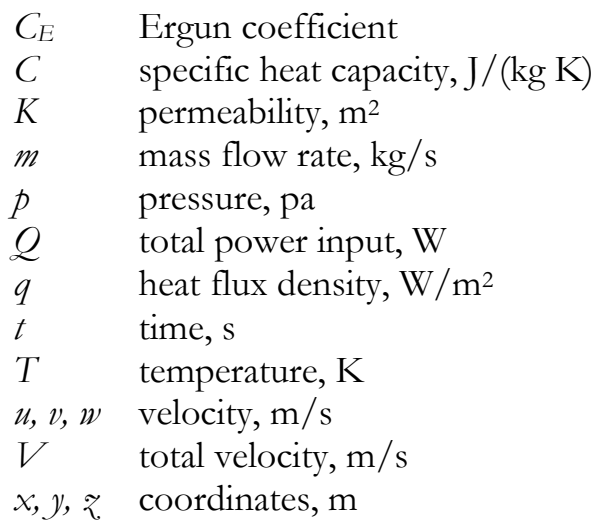

\section{Greek symbols}

\author{
$\varepsilon \quad$ porosity \\ $\lambda \quad$ thermal conductivity, $\mathrm{W} /(\mathrm{m} \mathrm{K})$
}




$$
\begin{array}{ll}
\mu & \text { kinematic viscosity, } \mathrm{m} / \mathrm{s}^{2} \\
\rho & \text { density, } \mathrm{kg} / \mathrm{m}^{3}
\end{array}
$$

\section{Subscripts}

$\begin{array}{ll}l & \text { liquid } \\ v & \text { vapour } \\ w & \text { wall }\end{array}$

\section{Acknowledgements}

The authors would like to express their appreciation to the Excellent Center for Sustainable Engineering (ECSE) of the Srinakharinwirot University (SWU) for providing financial support for this study. The authors also wish to acknowledge Fujikura Electronics (Thailand) Ltd. for their assistance in some of the vapor chamber samples.

\section{References}

[1] H. Y. Li, M. H. Chiang, C. I. Lee, and W. J. Yang, "Thermal performance of plate-fin vapor chamber heat sinks," Int. J. Heat Mass Transfer, vol. 37, pp. 731-738, 2010.

[2] T. E. Tsai, H. H. Wu, C. C. Chang, and S. L. Chen, "Two-phase closed thermo syphon vaporchamber system for electronic cooling," Int. Communications in Heat and Mass Transfer, vol. 37, pp. 484 489, 2010.

[3] T. H. Wang, C. C. Lee, and Y. S. Lai, "Thermal characteristics evaluation for board-level high performance flip-chip package equipped with vapor chamber as heat spreader," Microelectronic Engineering, vol. 87, pp. 2463-2467, 2010.

[4] H. Y. Li and M. H. Chiang, "Effects of shield on thermal-fluid performance of vapor chamber heat sink," Int. J. Heat and Mass Transfer, vol. 54, pp. 1410-1419, 2011.

[5] S. C. Wong, S. F. Huang, and K. C. Hsieh, "Performance tests on a novel vapor chamber," Applied Thermal Engineering, vol. 31, pp. 1757-1762, 2011.

[6] A. A. A. Attia and B. T. A. El-Assal, "Experimental investigation of vapor chamber with different working fluids at different charge ratios," Ain Shams Engineering Journal, vol. 3, pp. 289-297, 2012.

[7] J. Choi, M. Jeong, J. Yoo, and M. Seo, "A new CPU cooler design based on an active cooling heatsink combined with heat pipes," Applied Thermal Engineering, vol. 44, pp. 50-56, 2012.

[8] M. Crepinsek and C. Park, "Experimental analysis of pump-assisted and capillary-driven dualevaporators two-phase cooling loop," Applied Thermal Engineering, vol. 38, pp. 133-142, 2012.

[9] M. H. A. Elnaggar, M. Z. Abdullah, and M. A. Mujeebu, "Characterization of working fluid in vertically mounted finned U-shape twin heat pipe for electronic cooling," Energy Conversion and Manage, vol. 62, pp. 31-39, 2012.

[10] X. Ji, J. Xu, and A. M. Abanda, "Copper foam based vapor chamber for high heat flux dissipation," Experimental Thermal and Fluid Science, vol. 40, pp. 93-102, 2012.

[11] P. Naphon, S. Wongwises, and S. Wiriyasart, "On the thermal cooling of central processing unit of the PCs with vapor chamber," Int. Communication in Heat and Mass Transfer, vol. 39, pp. 1165-1168, 2012.

[12] M. Reyes, D. Alonso, J. R. Arias, and A. Velazquez, "Experimental and theoretical study of a vapour chamber based heat spreader for avionics applications," Applied Thermal Engineering, vol. 37, pp. 51-59, 2012.

[13] T. Saenen and M. Baelmans, "Numerical model of a two-phase microchannel heat sink electronics cooling system," Int. J. Thermal Sciences, vol. 59, pp. 214-223, 2012.

[14] Y. T. Chen, S. W. Kang, Y. H. Hung, C. H. Huang, and K. C. Chien, "Feasibility study of an aluminum vapor chamber with radial grooved and sintered powders wick structures," Applied Thermal Engineering, vol. 51, pp. 864-870, 2013.

[15] H. Hassan and S. Harmand, "3D transient model of vapour chamber: Effect of nanofluids on its performance," Applied Thermal Engineering, vol. 51, pp. 1191-1201, 2013. 
[16] P. Naphon, S. Wongwises, and S. Wiriyasart, "Application of two-phase vapor chamber technique for hard disk drive cooling of PCs," Int. Communication in Heat and Mass Transfer, vol. 40, pp. 32-35, 2013.

[17] H. Peng, J. Li, and X. Ling, "Study on heat transfer performance of an aluminum flat plate heat pipe with fins in vapor chamber," Energy Conversion and Management, vol. 74, pp. 44-50, 2013.

[18] Y. Peng, W. Liu, N. Wang, Y. Tian, and X. Chen, "A novel wick structure of vapor chamber based on the fractal architecture of leaf vein," Int. J. Heat and Mass Transfer, vol. 63, pp. 120-133, 2013.

[19] M. C. Tsai, S. W. Kang, and K. V. de Paiva, "Experimental studies of thermal resistance in a vapor chamber heat spreader," Applied Thermal Engineering, vol. 51, pp. 1191-1201, 2013.

[20] J. P. Van Doormal and G.D. Raithby, "Enhancements of the SIMPLEC method for predicting incompressible fluid flows," Numerical Heat Transfer, vol. 7, pp. 147-163, 1984. 
